\title{
Behaviour of Tall Buildings using Tuned Mass Dampers
}

\author{
Ubair Gul Khan \\ Department of Civil Engineering \\ Al-Falah University, Dhauj Faridabad
}

\author{
Mirza Aamir Baig \\ Department of Civil Engineering \\ Al-Falah University, Dhauj Faridabad
}

\begin{abstract}
Incalculable elevated structure has been built everywhere on over the world and the number is expanding step by step. This isn't just because of worried over high thickness of populace in the urban communities, business zones and space sparing yet additionally to build up land marks. As the seismic burden following up on a structure is a component of oneself load of the structure these structures are made similarly light and adaptable which have moderately low common damping, and in this manner the structures become more vibration inclined under wind and tremor stacking. To guarantee the useful execution of tall structures, different plan adjustments are conceivable, extending from elective basic frameworks to the use of inactive and dynamic control gadgets. This paper presents an outline of cutting-edge measures to lessen basic reaction of tall structures, including a conversation of assistant damping gadgets for moderating the seismic tremor and wind-initiated movement of structures. To guarantee the useful execution of tall structures, different plan adjustments are conceivable, running from elective auxiliary frameworks to the use of aloof and dynamic control gadgets. Latent tuned mass damper (TMD) is broadly used to control auxiliary vibration under wind load yet its viability to lessen tremor-initiated vibration is a developing procedure.
\end{abstract}

Here an investigative examination is proposed to contemplate the adequacy of TMD to decrease auxiliary vibration in Tall Buildings. For this examination a 60m tall structure having 15 stories with a square arrangement of $20 \times 20 \mathrm{~m}$ has been displayed.

The viability of single TMD to lessen basic vibrations, is read for a variety of TMD mass proportion

Keywords:- Structural Motions, Damping, Passive and Active control devices, TMD, AMD

\subsection{INTRODUCTION}

Vibration might be brought about by natural powers following up on a structure, for example, wind or earthquakes, or by an apparently harmless vibration source causing reverberation that might be ruinous, terrible or basically badly arranged. The seismic waves will make structures influence and waver in different manners relying upon the recurrence and heading of ground movement, and the tallness and development of the structure. Seismic movement can cause extreme motions of the structure which may prompt even auxiliary disappointment. The power of wind against tall structures can make the head of high rises move significantly in excess of a meter. This movement can be through influencing or winding. Certain points of wind and streamlined properties of a structure can emphasize the development and cause movement infection in inhabitants and posture genuine functionality issues. To upgrade the useful execution of the structure against seismic and wind powers, an appropriate structure configuration is performed utilizing elective basic frameworks and by usage of different vibration control equipment.

\subsection{TUNED MASS DAMPERS (TMDs)}

TMDs being used, ordinarily oil dampers, thick and viscoelastic dampers Normally, a TMD comprises of an inertial mass appended to the structure area with most extreme movement, by and large close to the top, through a spring and damping component, ordinarily gooey and viscoelastic dampers. The recurrence of the damper is tuned to a specific auxiliary recurrence so when that recurrence is energized, the damper will resound out of stage with the basic movement. Vitality is disseminated by the damper dormancy power following up on the structure. The adequacy of TMDs is dictated by their dynamic qualities, stroke and the measure of the additional mass. Extra damping presented by the framework is additionally reliant on the proportion of the damper mass to the powerful mass of the structure in the method of intrigue, commonly coming about in TMDs, which weigh $0.25-1.0 \%$ of the structure's weight in the major mode (normally around 33\%). Regularly, dividing limitations won't license customary TMD designs, requiring the establishment of elective arrangements including multi-stage pendulums, modified pendulums, and frameworks with precisely guided slide tables, hydrostatic heading, and covered elastic direction. Curl springs or variable solidness pneumatic springs commonly give the firmness to the tuning of TMDs.

In spite of the fact that TMDs are frequently viable, far superior reactions have been noted using different damper setups (MDCs) which comprise of a few dampers set in corresponding with appropriated characteristic frequencies around the control tuning recurrence (Kareem and Kline 1995).

Table 1. Mass support mechanisms and dampers for TMDs

\begin{tabular}{|l|l|}
\hline Mass Supporting Mechanism & Damper Attached to TMD \\
\hline Pendulum, including multiple type & Oil Dampers \\
\hline Roller Bearings \& Coil Springs & Viscous Dampers \\
\hline Laminated Rubber Bearings & Visco-Elastic Dampers \\
\hline
\end{tabular}



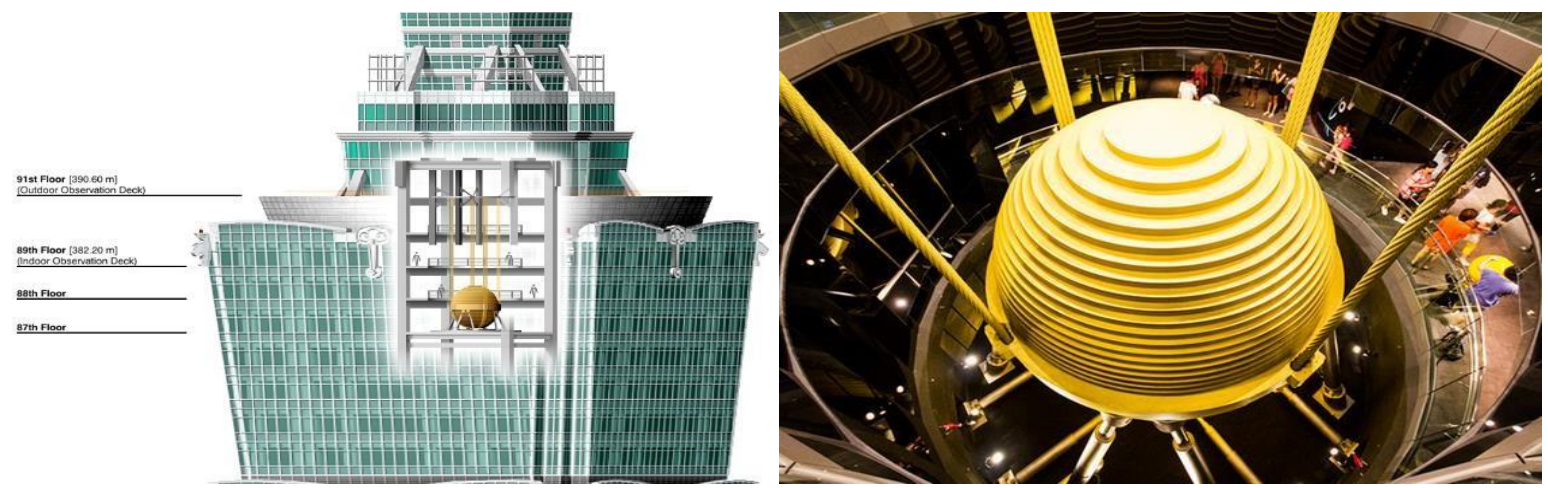

Figure 1. Tuned Mass Damper in Taipei 101.

\subsection{REAL LIFE STRUCTURES EQUIPPED WITH TMDs}

Tuned mass dampers have been used to improve the response of building structures under wind and seismic excitation. A short description of the several building structures that are equipped with Tuned Mass Dampers (TMDs) follows.

\section{John Hancock Tower, Boston}

Perhaps the earliest utilization of this sort was introduced in June 1977 in the $244 \mathrm{~m}$ (60 story) John Hancock Tower in Boston. Two TMDs were introduced at furthest edges of the 58th floor, at a dispersing of $67 \mathrm{~m}$, so as to check influence just as the torsional movement because of the state of the structure. Every damper estimated about 5.2x5.2x1 m and was basically a steel box loaded up with lead, weighing 300 tons, connected to the edge of the structure by solid springs. The lead-filled weight slides to and fro on a hydrostatic bearing comprising of a slight layer of oil constrained through openings in the steel plate. At whatever point the level quickening surpasses $0.003 \mathrm{~g}$ for two sequential cycles, the framework is naturally actuated. This framework is relied upon to lessen the influence of the structure by 40 to half.

\section{Citicrop Centre, New York}

Another spearheading utilization of TMDs has been in the Citicorp Building in New York. The stature of the structure is $278 \mathrm{~m}$ with major time of around $6.5 \mathrm{~s}$ and damping proportion of $1 \%$ along the two tomahawks. The framework, estimating $9.14 \times 9.14$ x $3.05 \mathrm{~m}$, comprises of a 410-ton solid square upheld on a progression of twelve 60 -cm distance across water powered weight offset heading with two spring damping instruments, one for the north-south movement and one for the east-west movement, was introduced in the 63rd floor in 1978. The framework lessens the breeze actuated reaction of the Citicorp working by $40 \%$ in both the north-south and east-west bearings, at the same time (Wiesner 1979). The damper framework is initiated naturally at whatever point the flat quickening surpasses $0.003 \mathrm{~g}$ for two successive cycles and will consequently close itself down when the structure speeding up doesn't surpass $0.00075 \mathrm{~g}$ in either hub over a 30-minute span.

\section{Chiba Port Tower, Japan}

Chiba Port Tower, a steel structure of $125 \mathrm{~m}$ in tallness and having a rhombus-formed arrangement with a side length of $15 \mathrm{~m}$ (finished in 1986) was the main pinnacle in Japan to be outfitted with a TMD. The timespan in the first and second method of vibrations are $2.25 \mathrm{~s}$ and $0.51 \mathrm{~s}$, separately for the $\mathrm{x}$ course and $2.7 \mathrm{~s}$ and $0.57 \mathrm{~s}$ for the $\mathrm{y}$ heading individually. Damping for the crucial mode was figured at $0.5 \%$. For higher method of vibration damping proportions relative to frequencies were expected in the examination. The utilization of the TMD was to build damping of the primary mode for both the $\mathrm{x}$ and $\mathrm{y}$ bearings. The mass proportion of the damper regarding the modular mass of the principal mode was around 1/120 in the $\mathrm{x}$ course and 1/80 in the $\mathrm{y}$ heading; periods in the $\mathrm{x}$ and $\mathrm{y}$ bearings of $2.24 \mathrm{~s}$ and $2.72 \mathrm{~s}$, individually; and a damper damping proportion of $15 \%$. Decrease $\mathrm{s}$ of around 30 to $40 \%$ in the relocation of the highest level and $30 \%$ in the pinnacle twisting minutes are normal.

\section{Taipei 101, Taiwan}

Taipei 101, a steel propped assembling is the third tallest structure on the planet. A circle formed TMD of weight 660 ton and width $5.5 \mathrm{~m}$ has been introduced between 88th to $92 \mathrm{nd}$ floor of the structure as appeared in Figure 1.5. This is a case of a pendulum type Tuned Mass Damper. The tremendous circle was suspended by four arrangement of links, and the dynamic vitality is scattered by eight water powered cylinders each having length of 2

$\mathrm{m}$. The damper can lessen $40 \%$ of the pinnacle development. Another two tuned mass dampers, each gauging 6 metric tons sit at the tip of the tower. These forestall harm to the structure because of solid breeze loads.

\section{Burj Al Arab, Dubai}

In the world's tallest hotel Burj Al Arab is equipped with 11 TMDs have been installed at different locations to control the wind induced vibration.

\section{Vi. Atc Tower in New Delhi, India}

A 50-ton Tuned Mass damper has been installed just beneath the ATC floor at 90m level. 


\section{Vii. Statue of Unity, India}

In the world's tallest statue, the Statue of Unity (182m high) two 200-ton Tuned mass dampers has been installed at the shoulder level.

\subsection{EQUATIONS OF MOTION}

In this section, the concept of the tuned mass damper is illustrated using the two-mass system shown in Figure 5. Here, the subscript $d$ refers to the tuned mass damper; the structure is idealized as a single degree of freedom system. Hence the following notation can be defined as,

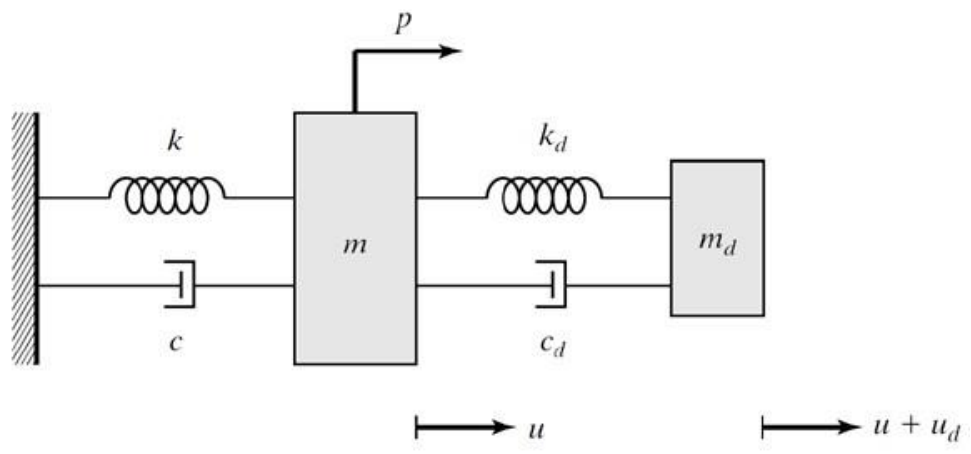

Figure 2 SDOF-TMD System.

and the equation of motion for the tuned mass is given by

$$
u \ddot{u_{d}}+2 \xi \xi_{d d} \omega \omega_{d d} u u_{d d}+\omega \omega_{d d^{2}} u u_{d d}=-u \ddot{u}
$$

The purpose of adding the mass damper is to limit the motion of the structure when it is subjected to a particular excitation. The design of the mass damper involves specifying the mass $m m_{d d}$, stiffness $k k_{d d}$, and damping coefficient $c c d d$. The damper is tuned to the fundamental frequency of the structure such that

$$
\omega \omega_{d d}=\omega \omega
$$

The stiffness's for this frequency combination are related by

$$
k k_{d d}=m m k k
$$

Considering the primary mass is subjected to the following periodic sinusoidal excitation,

$$
p p=p \hat{p} \sin \Omega \Omega \Omega \Omega
$$

then the response is given by

$$
\begin{aligned}
& u u=u u \sin \left(\Omega \mathrm{t}+\delta_{1}\right) \\
& u u_{d d}=u u_{d d} \sin \left(\Omega \mathrm{t}+\delta_{1}+\delta_{2}\right)
\end{aligned}
$$

where $u u$ and $\delta$ denote the displacement amplitude and phase shift, respectively. The critical loading scenario is the resonant condition, $\Omega=\omega$.

\subsection{DESIGN OF A TUNED MASS DAMPER}

The design of a damped TMD for an un-damped structure involves the following steps:

- $\quad$ Establish the allowable values of displacement of the primary mass and the TMD for the design loading.

- $\quad$ Determine the mass ratios required to satisfy these motion constraints from Figure 3.8 and Figure 3.9. Select the largest value of $\mathrm{mm}$.

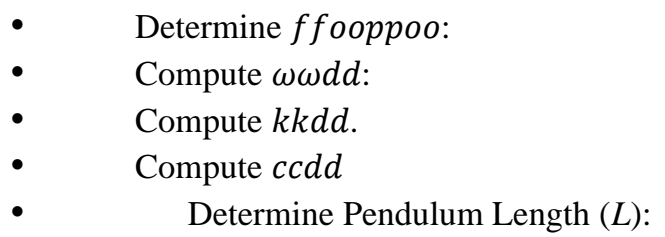

\subsection{MODEL CONSIDERED FOR ANALYSIS}

The models considered for investigation are test models and contextual analysis models. It has been endeavored to choose models which are both delegate and demonstrative of the real conduct of the genuine structures. The structure is $60 \mathrm{~m}$ high and has an arrangement measurement of 20x20m. The auxiliary arrangement of the structure is a "Fortified cement SMRF" framework. Sidelong burden opposing components are square RCC segments of size 500x500 mm divided at 5m in both X and Y tomahawks. The floor is a $125 \mathrm{~mm}$ thick RCC piece upheld by RCC light emissions 300x500 mm. The evaluation of cement for pieces, bars and sections is M30. Four quantities of 3-D FEM model of the 15 story building has been made utilizing the auxiliary investigation 
and structure programming ETABS. The chunks have been demonstrated as a Membrane component just to move the floor burdens to the shafts. The bars and segments have been displayed as Frame components. All the models are indistinguishable and have same stacking and part properties. The principal model is being utilized as a base model for computing the central normal time of the structure and for examination of the outcomes. The Pendulum type TMDs have been added to the remainder of three model, with mass proportions of 0.01, 0.02 and 0.04 as recorded in Table 4.2. The TMDs has been demonstrated at the focal point of the structure at the rooftop level, with a direct spring appended to the structure toward one side and at the free end the mass is relegated. The various boundaries of the TMDs have been recorded in Table 3.

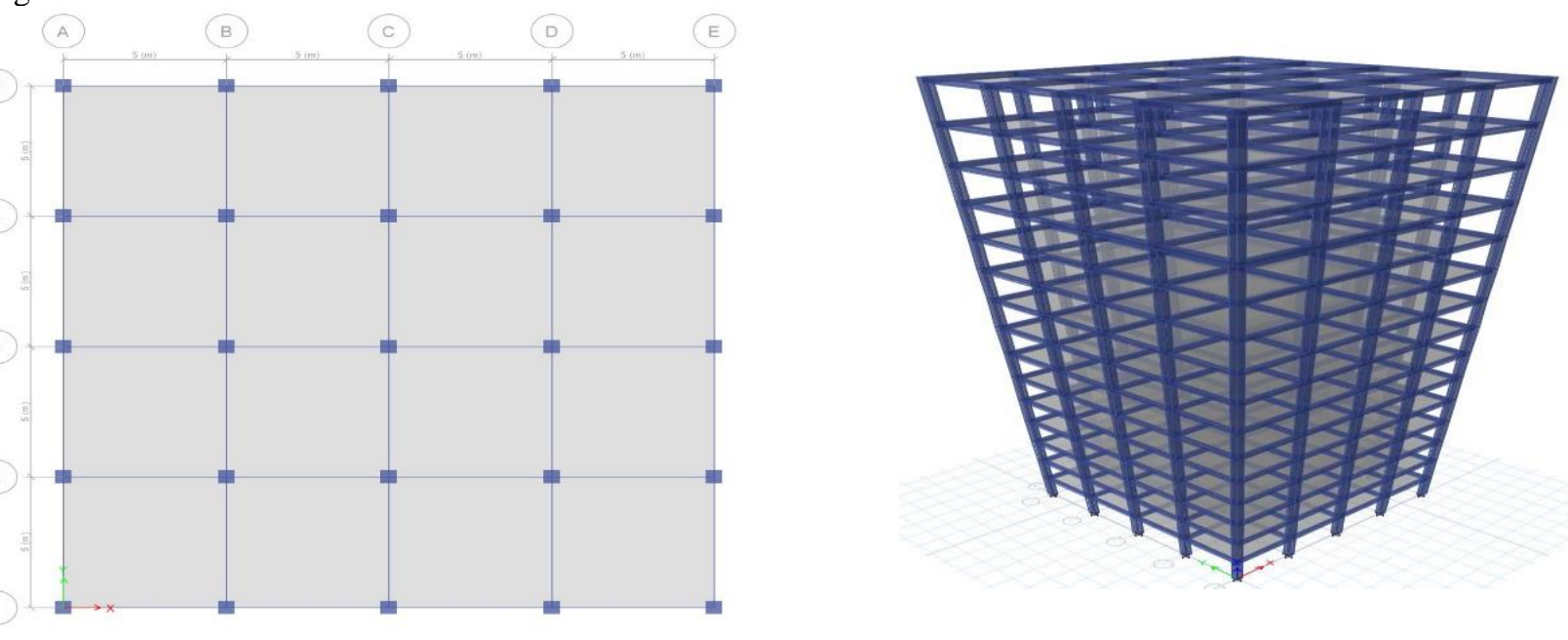

Table 2 Model ID

\begin{tabular}{|l|l|}
\hline Model ID & Description \\
\hline Model-1 & Base model without TMD \\
\hline Model-2 & Model with TMD having mass ratio $\mathrm{mm}=0.01$ \\
\hline Model-3 & Model with TMD having mass ratio $\mathrm{mm}=0.02$ \\
\hline Model-4 & Model with TMD having mass ratio $\mathrm{mm}=0.04$ \\
\hline
\end{tabular}

\subsection{CALCULATION OF TMD PARAMETERS}

Based on the modal analysis results of the base model, different parameters of the TMDs have been calculated using the guidelines mentioned earlier in Section 3.2.3. The calculated parameters of the TMDs with mass ratios 0.01, 0.02 and 0.04 are listed below in Table 3.

Table 3 Tuned Mass Damper parameters

\begin{tabular}{|l|c|c|c|c|c|}
\hline \multicolumn{2}{|c|}{ Description } & \multicolumn{2}{c|}{ TMD Parameters for mass ratios } & \multirow{2}{*}{ Units } \\
\cline { 2 - 6 } & Symbol & $\mathbf{1 \%}$ & $\mathbf{2 \%}$ & $\mathbf{4 \%}$ & \\
\hline Fundamental period of the building & $T T$ & 3.552 & 3.552 & 3.552 & $\mathrm{sec}$ \\
\hline Angular frequency of building & $\omega \omega$ & 1.769 & 1.769 & 1.769 & $\mathrm{rad} / \mathrm{s}$ \\
\hline Seismic weight of the building & $W W$ & 87025 & 87025 & 87025 & $\mathrm{kN}$ \\
\hline Modal participating mass ratio & & 0.75 & 0.75 & 0.75 & \\
\hline Participating mass in 1st mode & $\mathrm{m}$ & 6656 & 6656 & 6656 & $\mathrm{~T}$ \\
\hline Adopted mass ratio for TMD & $m m$ & 0.01 & 0.02 & 0.04 & \\
\hline Mass of the TMD & $m m_{d d}$ & 67 & 133 & 266 & Ton \\
\hline Weight of the TMD & $W W_{d d}$ & 657 & 1304 & 2609 & $\mathrm{kN}$ \\
\hline Optimal tuning frequency ratio & $f f_{\text {ooppoo }}$ & 0.988 & 0.975 & 0.952 & \\
\hline Optimal angular frequency of TMD & $\omega \omega_{d d}$ & 1.747 & 1.726 & 1.684 & $\mathrm{rad} / \mathrm{s}$ \\
\hline Pendulum length required & $L$ & 3.213 & 3.294 & 3.459 & $\mathrm{~m}$ \\
\hline Link stiffness in U1 direction & $k k d d 1$ & 45440 & 87990 & 167585 & $\mathrm{kN} / \mathrm{m}$ \\
\hline Link stiffness in U2 direction & $k k d d 2$ & 204 & 396 & 754 & $\mathrm{kN} / \mathrm{m}$ \\
\hline Link stiffness in U3 direction & $k k d d 3$ & 204 & 396 & 754 & $\mathrm{kN} / \mathrm{m}$ \\
\hline Optimal damping ratio for TMD & $\xi \xi d d o o p p o o$ & 0.060 & 0.085 & 0.118 & \\
\hline Linear damping coefficient & $c c_{d d}$ & 14.13 & 39.87 & 111.44 & $\mathrm{kN}-\mathrm{s} / \mathrm{m}$ \\
\hline
\end{tabular}

- A linear 2-noded link is added to the structure at the roof level with start node attached to the roof framing and the end node hanging freely.

- Now the TMD mass $m m_{d d}$ is assigned as special mass to the end node of link and the TMD weight is assigned to the same node as a gravity load in the Self weight load case. The Self-weight load case shall contain only the self-weight of the structure and the weight of the TMD.

- The link stiffness's $k k d d_{1}, k k_{d d 2}$ and $k k_{d d 3}$ are specified in the link property. The linear damping coefficient $c c_{d d}$ is also specified in the link property. 
- "Element Self Mass and Additional Mass" must be included in the Mass Source. Mass from "Specified Load Patterns" shall also be included but the Self-weight load pattern (which contains only the self-weight of the structure and the weight of the TMD) shall not be included as it has already been included through the "Element Self Mass and Additional Mass".

Table 4 Comparison of Response Spectrum Modal Information

\begin{tabular}{|c|c|c|c|c|c|c|c|}
\hline \multirow{2}{*}{ Model } & \multirow{2}{*}{$\mathrm{mm}$} & \multicolumn{2}{|c|}{ Period } & \multicolumn{2}{|c|}{ Effective Damping } & \multicolumn{2}{|c|}{ U1/U2Acc } \\
\hline & & $\mathrm{sec}$ & change & $\%$ & change & $\mathrm{m} / \mathrm{sec}^{2}$ & change \\
\hline Model-1 & 0.00 & 3.552 & - & $5.00 \%$ & - & 0.215 & - \\
\hline Model-2 & 0.01 & 3.814 & $7.38 \%$ & $8.01 \%$ & $60.2 \%$ & 0.177 & $17.67 \%$ \\
\hline Model-3 & 0.02 & 3.939 & $10.90 \%$ & $9.27 \%$ & $85.4 \%$ & 0.164 & $23.72 \%$ \\
\hline Model-4 & 0.04 & 4.143 & $16.64 \%$ & $11.09 \%$ & $121.8 \%$ & 0.153 & $28.83 \%$ \\
\hline
\end{tabular}

\subsection{RESULTS AND DISCUSSIONS.}

\section{Comparison of Base Reactions}

The base reactions from the models Model-1, Model-2, Model-3 and Model-4 are listed below in Tables 4.

Table 4 Comparison of Base Reactions

\begin{tabular}{|c|c|c|c|c|c|c|c|c|}
\hline \multirow{3}{*}{ Output Case } & \multicolumn{2}{|c|}{ Model-1 } & \multicolumn{2}{|c|}{$\begin{array}{c}\text { Model-2 } \\
m m=00.0000\end{array}$} & \multicolumn{2}{|c|}{$\begin{array}{c}\text { Model-3 } \\
m m=00.0000\end{array}$} & \multicolumn{2}{|c|}{$\begin{array}{c}\text { Model-4 } \\
m m=00.0000\end{array}$} \\
\hline & FX & FY & FX & FY & FX & FY & FX & FY \\
\hline & $\mathrm{kN}$ & $\mathrm{kN}$ & $\mathrm{kN}$ & $\mathrm{kN}$ & $\mathrm{kN}$ & $\mathrm{kN}$ & $\mathrm{kN}$ & $\mathrm{kN}$ \\
\hline EQX & -1750 & 0 & -1764 & 0 & -1777 & 0 & -1803 & 0 \\
\hline EQY & 0 & -1750 & 0 & -1764 & 0 & -1777 & 0 & -1803 \\
\hline WLX & -2030 & 0 & -2030 & 0 & -2030 & 0 & -2030 & 0 \\
\hline WLY & 0 & -2030 & 0 & -2030 & 0 & -2030 & 0 & -2030 \\
\hline SPECX & 1750 & 0 & 1504 & 367 & 1438 & 348 & 1388 & 305 \\
\hline SPECY & 0 & 1750 & 367 & 1504 & 348 & 1438 & 305 & 1388 \\
\hline TH_Bhuj & 1179 & 1521 & 1399 & 1513 & 1339 & 1450 & 1230 & 1327 \\
\hline TH_Bhuj & -1751 & -1749 & -1730 & -1782 & -1656 & -1757 & -1463 & -1679 \\
\hline
\end{tabular}

From the above results it can be seen that with the addition of the TMD,

the Base Shears of the building have changed except for the Wind load case. Since the effect of the TMD is supposed to be captured in the Modal analysis cases only, there should not be any change in the Base Shear for EQX, EQY, WLX and WLY as these are Static load cases. But the increase in Base Shear for EQX and EQY with the increasing mass ratio of the TMD is because of the static weight of the TMD and the increment is $A A_{h}$ times the weight of TMD, which is usual.

For the Response Spectrum load cases SPECX and SPECY, the Base Shear has reduced with the increasing mass ratio, compared to the base model. The reduction in Base Shear is $14.06 \%, 17.82 \%$ and $20.69 \%$ for the TMD mass ratios of $0.01,0.02$ and 0.04 respectively.

For the Time History load case the change in the Base shear is not substantial for the TMD mass ratios of 0.01 and 0.02 , but the Base Shear has decreased by $16.45 \%$ in $\mathrm{X}$ direction and $4.0 \%$ in Y direction for the mass ratio 0.04 .

\section{Comparison of Storey Displacements}

The storey displacements from the models Model-1, Model-2, Model-3 and Model-4 are shown below in Figures 4.18 and 4.19. The displacement responses of a joint at roof level for Time History load case are also shown in Figures 4.20, 4.21 and 4.22. From these results it can be seen that with the addition of the TMD, the storey displacements of the building have reduced significantly.

For the Response Spectrum load cases SPECX and SPECY, the reduction in storey displacements is $19.8 \%, 25.1 \%$ and $29.1 \%$ for the TMD mass ratios of $0.01,0.02$ and 0.04 respectively.

For the Time History load case the reduction in the storey displacements is $10.5 \%, 15.5 \%$ and $23.4 \%$ for the TMD mass ratios of $0.01,0.02$ and 0.04 respectively 

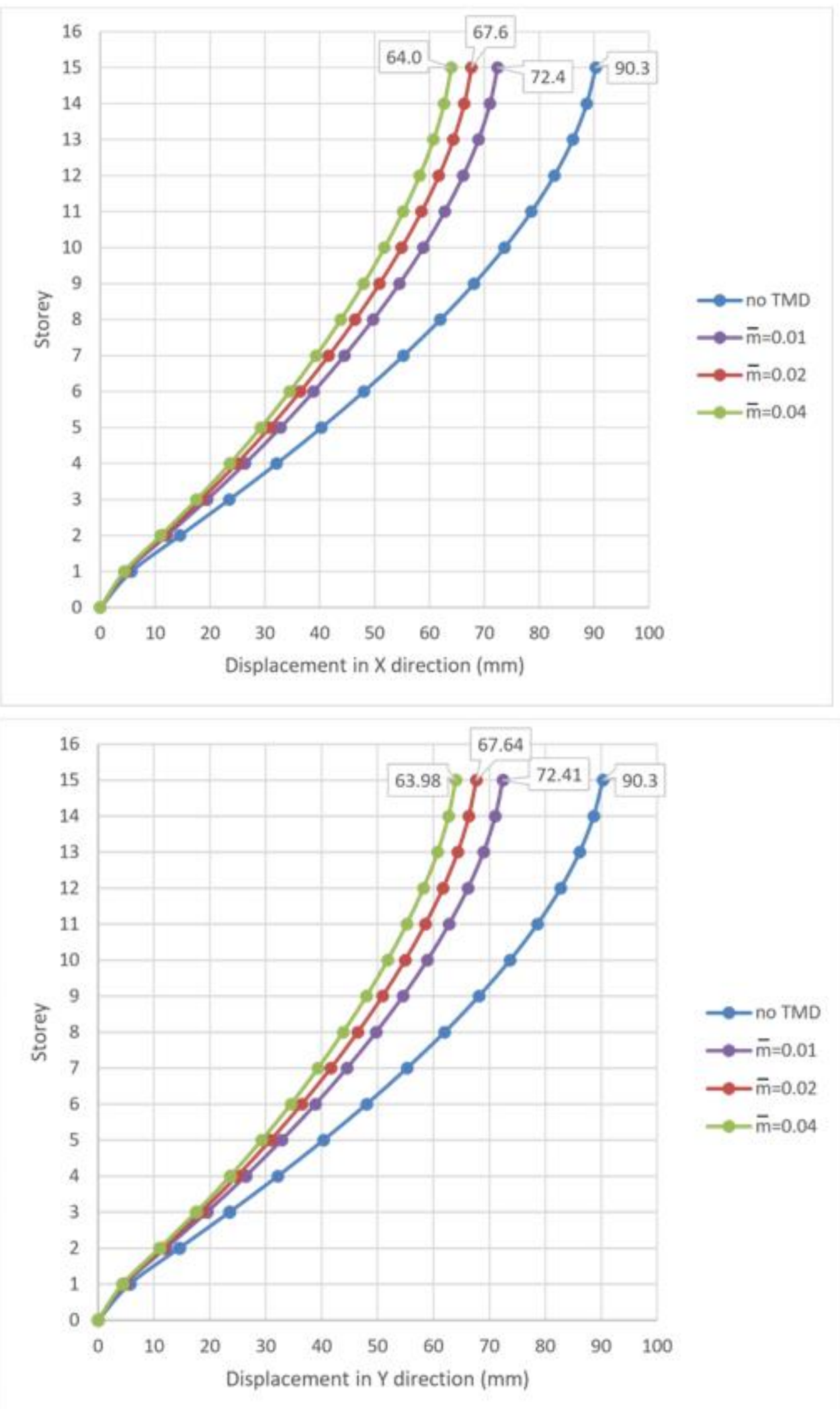

Figure 3 Storey Displacements for SPECX and SPECY 

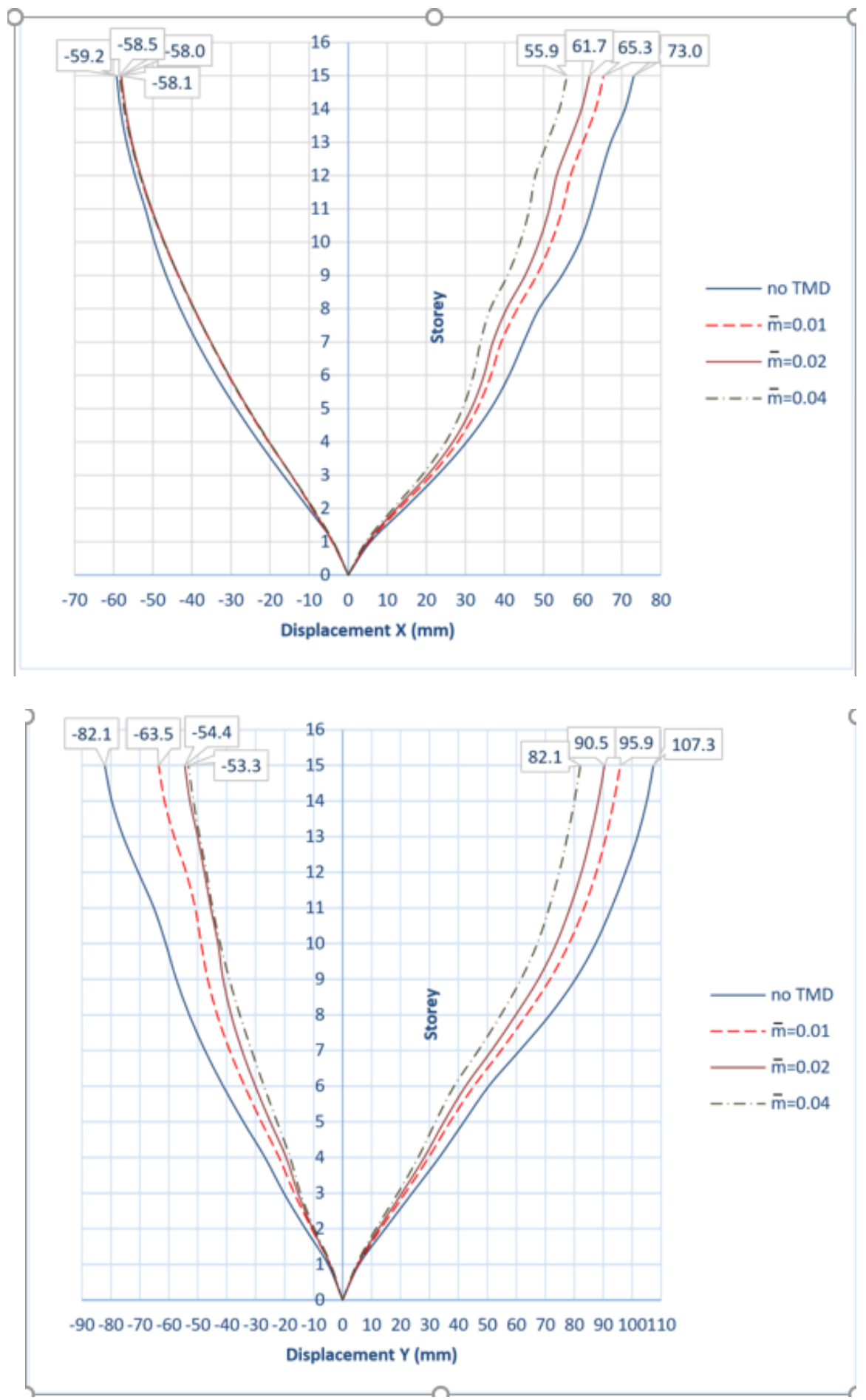

Figure 6 Storey Displacements for TH_Bhuj. 

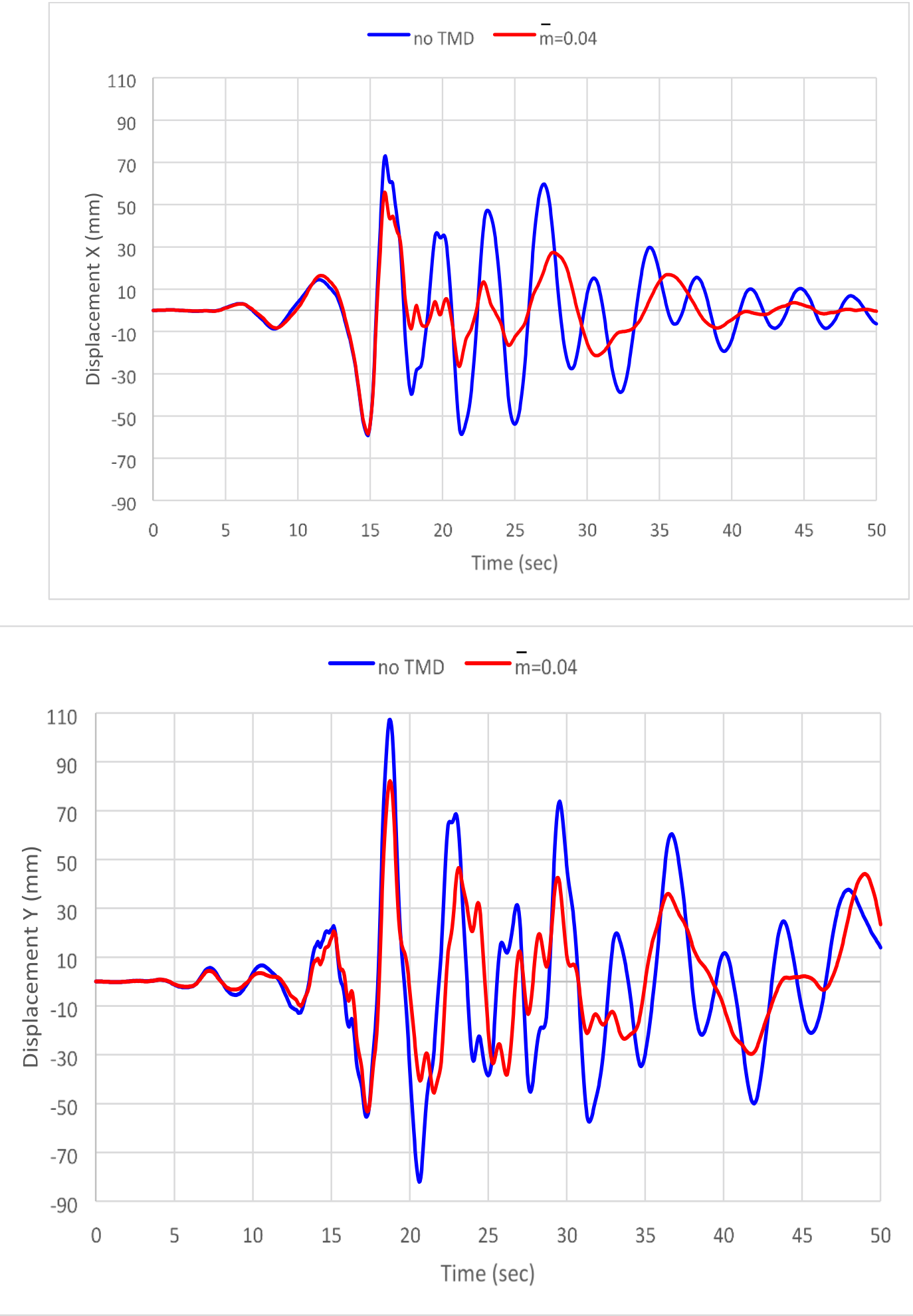

Figure 7 Joint Displacement at Roof Level for TH_Bhuj. 

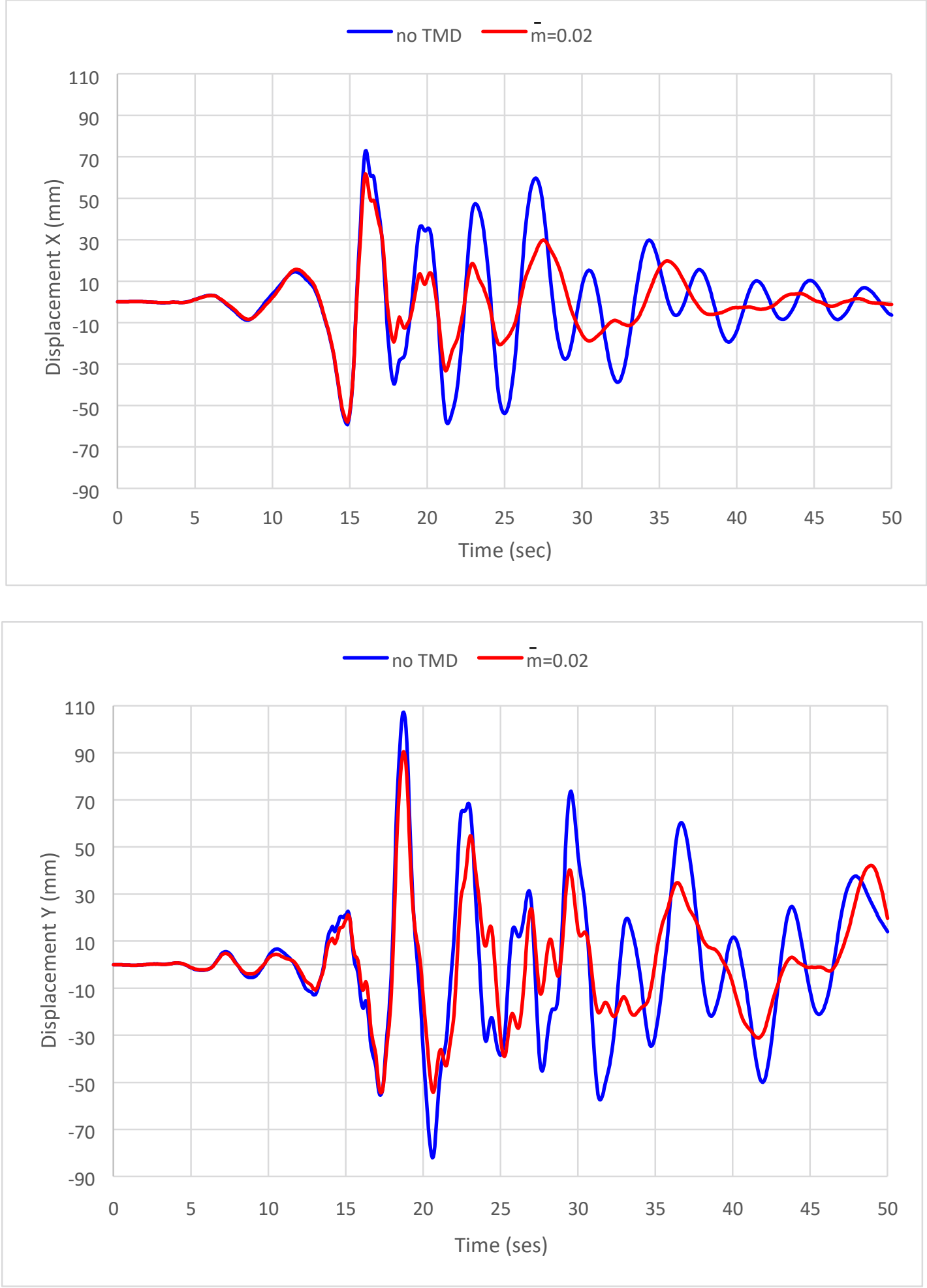

Figure 8 Joint Displacement at Roof Level for TH_Bhuj 


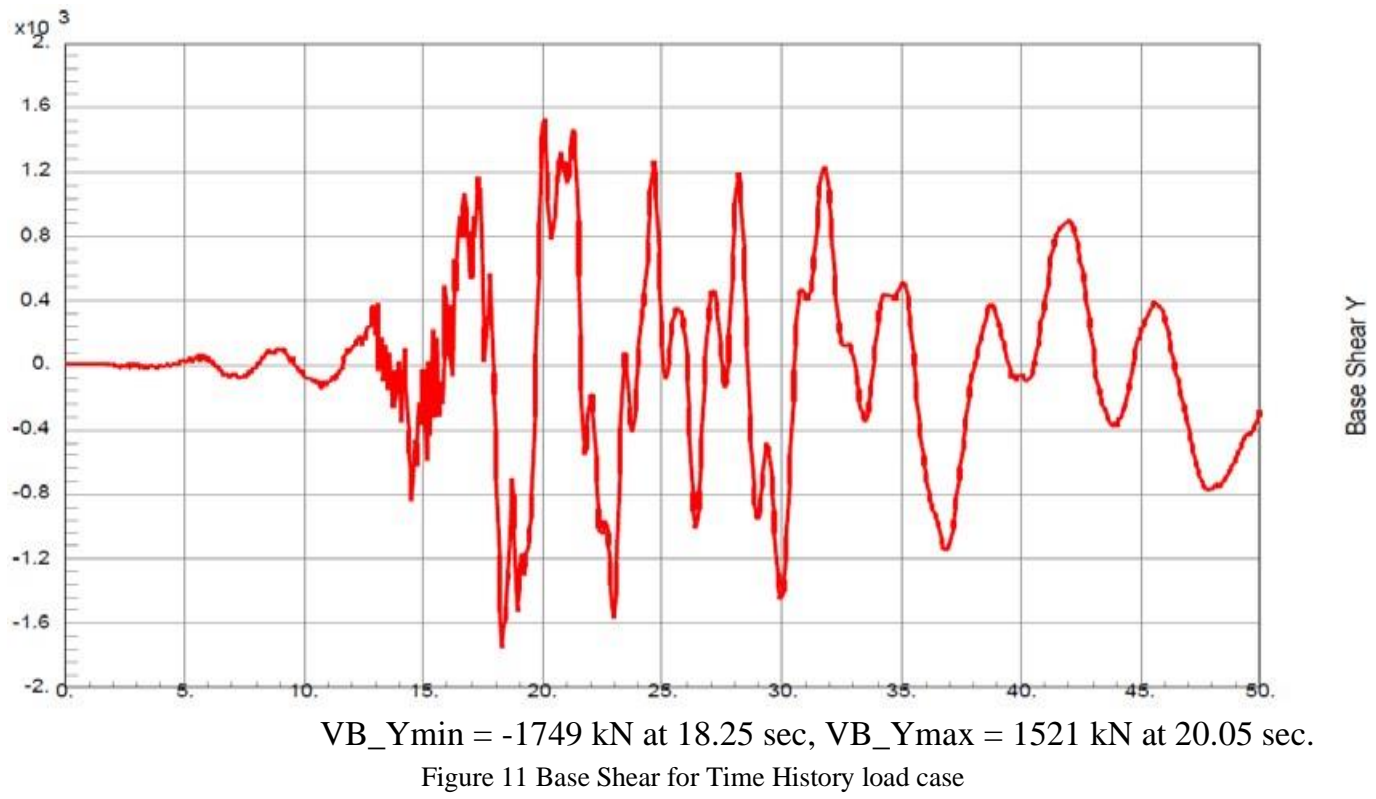

CONCLUSION

In the present study the 3D model considered is $60 \mathrm{~m}$ tall building having 15 storeys with floor to floor height of $4 \mathrm{~m}$. The building has a square plan of $20 \times 20 \mathrm{~m}$. In this study both the building and the damper has been modelled as linear. Four numbers of identical models were created, first model is the base model (uncontrolled) and the remaining three models (controlled) have TMDs with mass ratios of $0.01,0.02$ and 0.04 .

Linear time history analysis of the building has been done using the acceleration data of Bhuj/Kutch 2001 earthquake. Present study focused on the ability of TMD to reduce earthquake induced structural vibration and to compare the building response with effect of variation in mass ratio and damping ratio of TMD. From this study it can be concluded that.

The acceleration of the building in the fundamental mode is reduced by $17.67 \%, 23.72 \%$ and $28.83 \%$ for the mass ratios of $0.01,0.02$ and 0.04 respectively.

1) The effective damping of the building in the fundamental mode is increased to $8.01 \%, 9.27 \%$ and $11.09 \%$ for the mass ratios of $0.01,0.02$ and 0.04 respectively.

2) The maximum storey displacement of the building is reduced by $19.8 \%, 25.1 \%$ and $29.1 \%$ for the mass ratios of 0.01 , 0.02 and 0.04 respectively.

3) The effective damping of the building increases and the dynamic response of the building reduces as the mass ratio of the TMD is increased. The TMD becomes robust with increasing mass ratio. Hence an optimal mass ratio of the TMD can be found to reduce the building responses substantially there by giving a desired level of human comfort, safety and economy to the structure.

\section{Compliance with ethical standards}

Conflict of interest on behalf of all authors, the corresponding author states that there is no conflict of interest.

\section{REFERENCES}

[1] Kareem, A., Kijewski, Y, “Mitigation of Motions of Tall Buildings with Specific Examples of Recent Applications,” Wind and Structures., Vol. 2, No. 3, pp. 201-251 (1999).

[2] Introduction to Structural Motion Control, Jerome J. Connor.

[3] Seismic Analysis of Structures, T K Datta, IIT Delhi.

[4] IS1893 (Part-1): 2016 'Criteria for Earthquake Resistant Design of Structures'.

[5] IS 875 (Part-3): 2015 'Design Loads (Other than Earthquake) for Buildings and Structures, Part-3 - Wind Load'.

[6] Taylor, D.P. and M.C. Constantinou. (1996), Fluid Dampers for Applications of Seismic Energy Dissipation and Seismic Isolation, Publication of Taylor Devices, Inc., 1996

[7] Tamura, Y. (1997), Application of Damping Devices to Suppress WindInduced Responses of Buildings, Proceedings of the 2nd European and African Conference on Wind Engineering, Palazzo Ducale, Genova, Italy, 1:45-60.

[8] Sakamoto, M. (9-10 Dec. 1993), Practical Applications of Active Structural Response Control and Earthquake \&Strong Wind Observation Systems, Planning Workshop for the Hong Kong International Full-Scale Control TestFacility, Hong Kong University of Science \& Technology.

[9] Sakamoto, M. and Kobori, T. (Dec. 1996), Applications of Structural Response Control (Reviews from the Past and Issues Toward the Future), Proceedings of the Second International Workshop on Structural Control, Hong Kong.

[10] Kareem, A., (1983), Mitigation of Wind Induced Motion of Tall Buildings, Journal of Wind Engineering and Industrial Aerodynamics, 11(1-3): 273284.

[11] Kareem, A. (1990), Reduction of Wind Induced Motion Utilizing a Tuned Sloshing, Journal of Wind Engineering and Industrial Aerodynamics, 36: 72537.

[12] Kareem, A. (27-30 June 1993), Tuned Liquid Dampers: Past, Present, and

[13] Future, Proceedings of the 7th U.S. National Conference on Wind Engineering.

[14] Kareem, A., and M. Tognarelli. (Oct. 1994), Passive \& Hybrid Tuned Liquid Dampers, Structural Engineering Forum: 26-30. 
[15] Symans, M.D. and M.C. Constantiou. (1996), Experimental Study of Seismic Response of Structures with Semi-Active Damping Control Systems, Proceedings of Structures Congress X.IV, Chicago, April 15-18.

[16] Spencer, B.F. Jr., and M.K. Sain (1997), Controlling Buildings: A New Frontier in Feedback, IEEE Control Systems,17(6): 19-35.

[17] Chang, K.C., Soong, T.T., Oh, S-T., and M.L. Lai. (1992), Effect of Ambient Temperature on a Viscoelastically Damped Structure, Journal of Structural Engineering, ASCE, 118(7): 1955-1973.

[18] Kawamura, M., Maebayashi, K., and K. Shimada. (1993), Application of a Tuned Mass Damper System Using Laminated Rubber Bearings to a Tower Structure (Design, Test, and Recorded Vibration During Typhoons), Proc. of International Conference on Tall Buildings, Rio de Janerio.

[19] Mahmoodi, P., Robertson, L.E., Yontar, M., Moy, C., and L. Feld. (1987), Performance of Viscoelastic Structural Dampers in World Trade Center Towers, Dynamics of Structures, Structures Congress '87, Orlando, FL.

[20] Kitamura, H., Tamura, Y., and T. Ohkuma. (May 1995), Wind Resistant Design \& Response Control in Japan Part III: Structural Damping \& Response Control, Proceedings of 5th World Congress Council on Tall Buildings and Urban Habitat, Amsterdam.

[21] Soong, T.T. and G.F. Dargush. (1997), Passive Energy Dissipation Systems in Structural Engineering, Wiley \& Sons, New York.

[22] Housner, G.W., et al. (1997), Structural Control: Past, Present and Future, Special Issue of Journal of Engineering Mechanics, 123(9).

[23] Kwok, K.C.S. and N. Isyumov. (July 1998), Aerodynamic Measures to Reduce the Wind-Induced Response of Buildings and Structures, Proceedings of Structural Engineers World Congress, San Francisco, CD-ROM: T179-6. 